\title{
71266
}

Contribution from the World Bank to the G20 Commodity Markets Sub Working Group

The Role of Emerging-Market Economy

Demand during the Post-2005 boom

\section{April 2012}

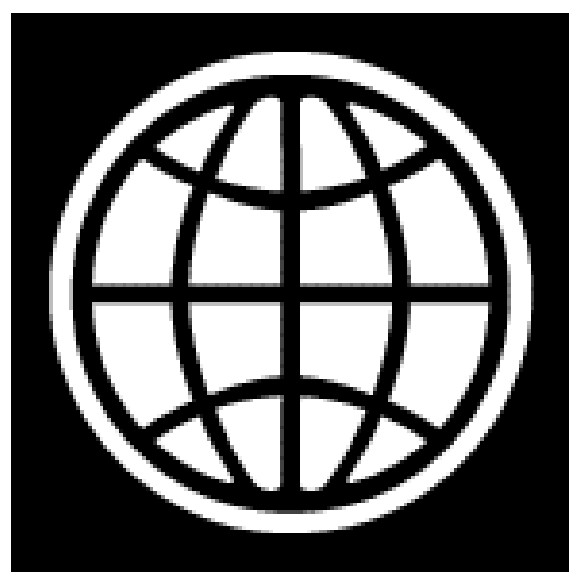




\section{Contribution to G20 COMmodity MARKets Sub Working GROUP ${ }^{1}$ April 12, 2012}

\section{The Role of Emerging-Market Economy demand during the Post-2005 Boom}

The post-2005 commodity price boom took place when most emerging-market economies (EMs) were experiencing strong and sustained economic growth, prompting numerous commentators to argue that a structural shift in the demand for commodities by emerging countries had occurred. Indeed, the size of China and India alone, which together account for 37 percent of the world's population, implies that even minor changes in their pattern of demand growth may have a measurable impact on world commodity prices. ${ }^{2}$ This note examines the role of demand by EMs for both extractive and food commodities. It concludes that a structural shift in metal demand has taken place, driven, for the most part, by China. Energy prices have also been influenced by EM demand. However, the role of demand for food commodities from EMs has been much less than what much of the literature argues.

\section{Extractive commodities}

Since 1990, China's refined metal consumption (aluminum, copper, lead, nickel, tin, and zinc) jumped 17-fold, and its share of world refined metal consumption grew from 5 to 41 percent. Its average annual rate of metal consumption growth since 2000 was 15 percent, while demand from the rest of the world has been essentially unchanged (Figure 1). Unquestionably, China has been a major driver of metals demand and higher prices, as the country consumed large quantities of metals for construction, infrastructure, and manufacturing. For example, China's metal intensity (metal use per $\$ 1,000$ of real GDP) was three times higher than the rest of the world back in 1990 and it reached almost nine times in 2008 (Figure 2). The surge in demand for industrial materials by China and its effect on prices have been discussed in various contexts. As early as 2005, there were warnings that China's metal demand would likely lead to a price super-cycle (i.e., a price cycle that lasts decades instead of a few years.) Indeed, econometric evidence has found strong support of the super-cycle hypothesis. ${ }^{3}$

India, with its large population, is often cited as the "next China" in terms of consumption of commodities. Its share of world metals consumption, however, is minuscule compared to that of China's having risen from 2 percent in 1990 to only 3 percent in 2010. India's relatively constant share of metal demand reflects, for the most part, the very different economic structure and the level and direction of investment, as well as domestic trade policies. Moreover, its pace of metal

\footnotetext{
${ }^{1}$ This note was prepared by World Bank staff John Baffes (DEC).

${ }^{2}$ Today's discussions bring to mind earlier calls for global action in food markets. For example, Meadows and others (1972), often referred to as the "Club of Rome", in response to the 1972 food price spike warned that the world was heading towards a Malthusian outcome (Meadows, Donella H., Dennis L. Meadows, Jørgen Randers, and William W. Behrens III, 1972, The Limits to Growth, Rome: Club of Rome). Two decades later, Brown (Brown, Lester R. (1995), Who Will Feed China? Wake-up Call for a Small Planet, Worldwatch Institute: USA) argued that strong food demand by China would put pressure on world markets in turn leading to unsustainable food price levels. Brown's book was published as China was beginning to open up to global markets.

${ }^{3}$ For such warnings, see Heap (2005) ("China-The Engine of a Commodities Super Cycle." Citigroup Smith Barney, New York City). Jerrett and Cuddington (2008) ("Broadening the Statistical Search for Metal Price Super Cycles to Steel and Related Metals" Resources Policy vol. 33, pp. 188-195) present econometric evidence on the super-cycle hypothesis.
} 
demand growth has been only half that of China.

The role of EM's demand in crude oil consumption has been equally important. Consider, for example, that in 1965, OECD countries accounted for three quarters of global crude oil consumption while in 2010 their share declined to 52.5 percent. On the other hand, China's and India's shares grew from 0.7 and 0.8 percent in 1965 to 10.4 and 3.8 percent in 2010 (Figure 3). During the past 15 years, non-OECD's share in oil consumption increased from 35 percent to 47 percent. More importantly, developing countries accounted for all the growth in global crude oil consumption of the past decade.

While it is clear that EM has played a key role during the post-2005 price boom, there are a number of differences when compared to the metal markets. First, China accounts for more than 40 percent of global metal consumption, but only 10 percent of oil consumption. Second, while non-OECD share increased considerably during the recent boom, there has been another episode of increase (from $26 \%$ to $36 \%$ during 1973-83). Third, as we move forward, it is unlikely that China's role in crude oil will be as important as it has been in metals during the past decade, for, at least, two reasons. First, its car fleet (where most of crude oil goes), is new and efficient. Second, there are other sources of energy that can be used as substitutes.

\section{Food commodities}

Contrary to energy and metal commodities where EM demand played (and still plays) a major role, demand by EMs did not play a key role in the post-2005 rise in the prices of food commodities contrary to what has been reported in various articles and reports. The June 2009 issue of National Geographic, for example, noted that “... as countries like China and India prosper and their people move up the food ladder, demand for grains has increased." Krugman (2008) has referred to "the growing number of people in emerging economies who are, for the first time, rich enough to start eating like Westerners." Likewise, Wolf (2008) has attributed the strong increase in food prices to "strong rises in incomes per head in China, India, and other emerging countries [which] have raised demand for food, notably meat and the related animal feeds."4

Using annual data for per capita cereal consumption from 1960 to 2009, World Bank staff estimated trends in per capita cereal consumption for five Asian countries: China, India, Indonesia, Japan, and Korea (Figure 4). The results show, for Japan and Korea, that initially consumption followed an upward path eventually reaching a peak during the mid-1980s in Japan and late1990s in Korea; it began declining in both countries and by 2009 (the most recent observation of the sample) it reached 1970 levels in Japan and 1987 levels in Korea. China, India, and Indonesia experienced increases in per capita cereal consumption as well. China's and Indonesia's consumption curve, however, flattened during the past decade with early signs of decline for Indonesia, albeit very slow. More interestingly, India's path resembles, to some extent, that of Japan and Korea in the sense that it reached a plateau during the 1990s and began declining since then. The declining per capita calorie intake in India has been well-documented, a surprising phenomenon in view of the increasing real income and real wages during the past decade. Deaton and Dréze (2008) concluded that such decline may be explained by declining levels of physical activ-

\footnotetext{
${ }^{4}$ Krugman, Paul (2008), “Grains Gone Wild.” Op-Ed, New York Times, April 7.Wolf, Martin (2008), "Food Crisis is a Chance to Reform Global Agriculture.” Financial Times, April 27.
} 
ity and various improvements in the health environment. ${ }^{5}$

Bank staff also examined the relationship between cereal consumption and income by estimating income elasticities. Two important results emerge from the analysis. First, as incomes rise, elasticities of both cereals and vegetable oils decline. For example, a 10 percent increase in per capita GDP is associated with a 6.5 percent increase in cereal consumption in poor countries (less than $\$ 1,000$ of income) and with only a 0.06 percent increase in high income countries (more than $\$ 20,000$ of income). More specifically, we find that China's income elasticity for cereals is 0.33 and India's is 0.44 in stark contrast to Japan (0.06) and Korea (0.09). Second, the elasticity estimates for vegetable oils is much higher than cereals, including high income countries. This is a well-documented result and reflects the fact that, even with rising incomes, people consume more edible oils as they tend to eat more in professional establishments and consume prepackaged foods, both high oil-content processes.

A different way to examine the role of EM demand is to look at the relationship between a country's share of global cereal consumption and its share of imports during the 1990s. Although China and India did, in fact, account for large shares of global cereal use, both were selfsufficient. On the other hand, Japan and a few other countries consumed less than 5 percent of global cereal production but accounted for a relatively large share of imports. The same broad pattern was in place during 2000-09, with some notable differences. The expansion of the EU (from EU-15 to EU-27) reduced its net exports, Russia became an exporter, and most importantly, China and India became net exporters as well.

Between 2003-05 and 2006-08 - two periods roughly corresponding to low price (pre-boom) and high price (boom) episodes - global cereal consumption increased by about six percent with remarkably similar contributions by developing and high income countries (table 2). Imports by developing countries increased 14.7 percent (versus 10.5 percent by high income countries), during this period. Exports from developing countries, however, increased by more than 27 percent while those of high income countries increased by a modest 2.3 percent. While imports to developing countries increased by more than imports to high income countries (14 percent compared with 10 percent), net imports to developing countries declined by 4 million tons while net imports to high income countries increased by 6 million tons. Stated otherwise, developing countries "gave" more cereals to the global market than what they "took away" during the recent boom years.

These statistics suggest that the role of demand by EMs was much more muted than what has been argued in much of the literature. Similar findings have been reported elsewhere. For example, Alexandratos (2008: 673), emphasized that the combined average annual increment in consumption for China and India (both growth rates and absolute increments) was lower in the years

\footnotetext{
${ }^{5}$ In particular, they state that "that there has been little net change in aggregate cereal (or cereal plus pulses) availability in India since independence and that there has been a clear downward trend since the early 1990 s ... one possible explanation for this drift is that calorie requirements have declined, due to better health as well as to lower activity levels" (Angus Deaton and Jean Dréze (2008), "Nutrition in India: Facts and Interpretations." Economic and Political Weekly, vol. 44, pp. 42-65).

${ }^{6}$ This is in contrast to the 1973 price spike where all of the increase in consumption came from developing countries.
} 
of the price surges, 2002-08, compared to 1995-2001. FAO (2009) arrived at nearly identical conclusions. Baffes and Haniotis (2010) analyzed consumption patterns of various commodities and concluded that the demand of beef, poultry, and pork in both China and India exhibited much lower rates of growth during 2003-08 than it did during 1997-2002 (on a few occasions the growth was negative). ${ }^{7}$

\section{Conclusion}

The post-2005 boom in commodity prices has triggered debate on its causes, with numerous commentators arguing that a key cause has been strong demand growth by large developing countries. This note argues that demand by China has played a central role in metal market. The role of EM demand has been very important in energy markets as well. However, EMs (including China and India) did not increase the consumption of cereals during the course of the boom.

It should be noted that the results reported here by no means imply that the levels of food consumption will decline as we move forward. On the contrary, as population grows (albeit at slower rates compared to the past) and incomes of poorer countries grow (where income elasticities are still high), the consumption needs of the world will increase accordingly.

Table 1: Crude oil consumption shares (percent), 1970-2010

\begin{tabular}{lrrrrr}
\hline \hline & $\mathbf{1 9 7 0}$ & $\mathbf{1 9 8 0}$ & $\mathbf{1 9 9 0}$ & $\mathbf{2 0 0 0}$ & $\mathbf{2 0 1 0}$ \\
EU & 36.9 & 35.5 & 33.1 & 30.6 & 29.9 \\
US & 32.4 & 27.9 & 25.5 & 25.7 & 21.9 \\
China & 1.2 & 2.8 & 3.5 & 6.2 & 10.4 \\
Japan & 8.5 & 8.0 & 7.9 & 7.2 & 5.1 \\
India & 0.9 & 1.1 & 1.8 & 3.0 & 3.8 \\
Russian Fed. & - & - & 7.6 & 3.5 & 3.7 \\
Saudi Arabia & 0.9 & 1.0 & 1.8 & 2.1 & 3.2 \\
Others & 19.2 & 23.7 & 18.8 & 21.7 & 22.0 \\
WORLD & 100.0 & 100.0 & 100.0 & 100.0 & 100.0 \\
\hline \hline
\end{tabular}

Source: BP Statistical Review

\footnotetext{
${ }^{7}$ Nikos Alexandratos (2008), "Food Price Surges: Possible Causes, Past Experience, and Long-term Relevance", Population and Development Review, vol. 34, pp. 599-629. John Baffes and Tassos Haniotis (2010) "Placing the Recent Commodity Boom into Perspective", in Food Prices and Rural Poverty, pp. 40-70, ed. A. Aksoy and B. Hoekman, Center of Economic and Policy Research and the World Bank. Food and Agriculture Organization of the United Nations (2009), The State of Agricultural Commodity Markets: High Food Prices and the Food Crisis-Experiences and Lessons Learned, Rome: FAO.
} 
Figure 1: Refined Metal Consumption

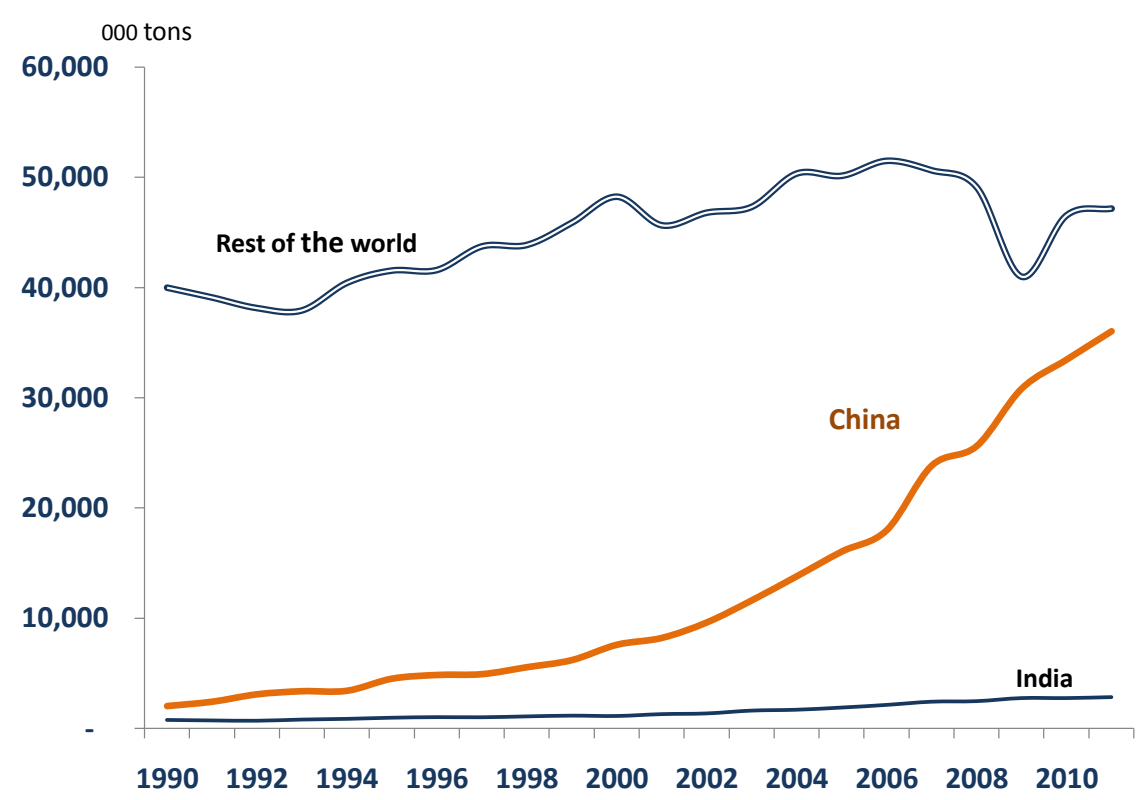

Figure 2: Metal Consumption Intensity

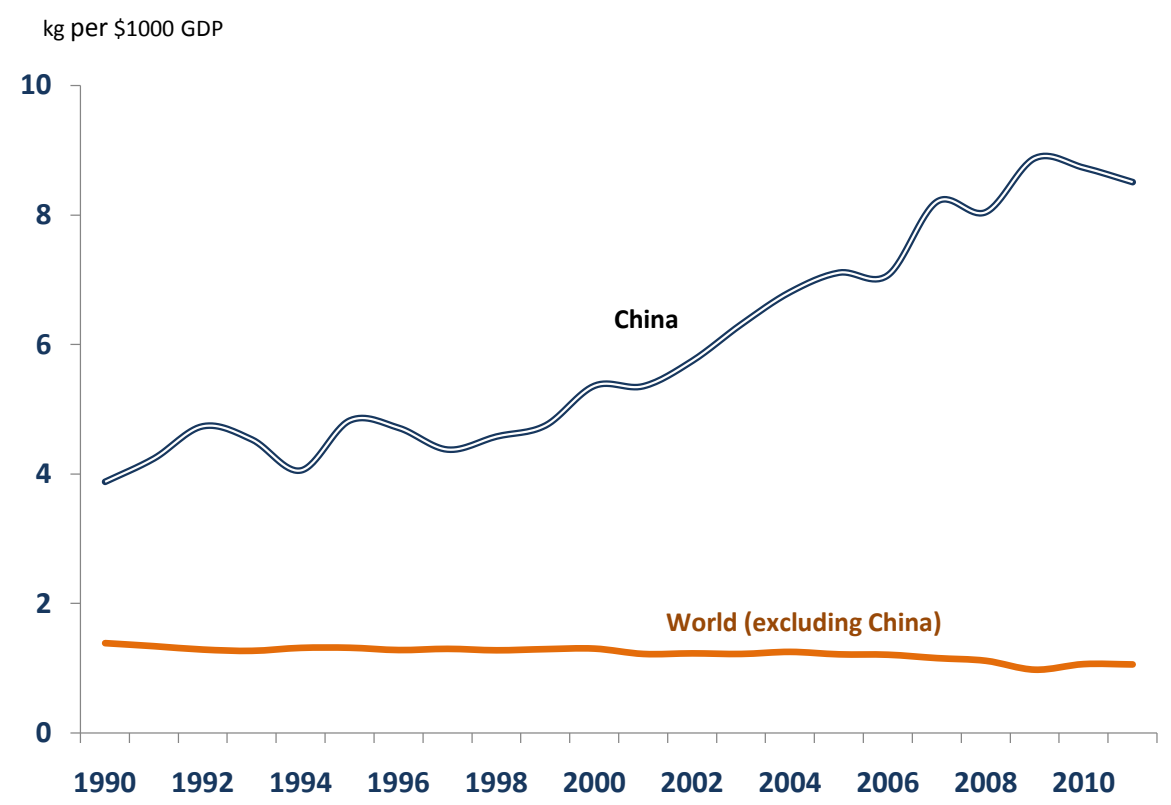




\section{Figure 3: World Oil Consumption}

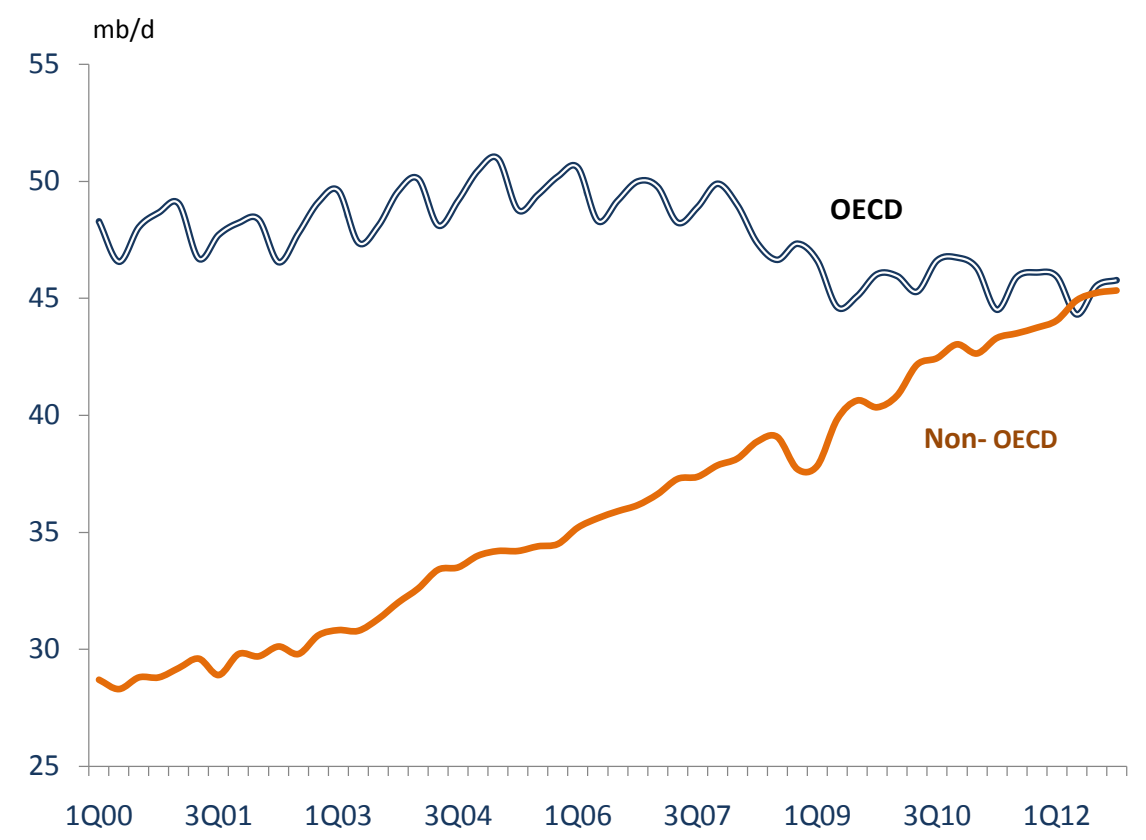

Figure 4: Cereal consumption in various Asian countries (per capita kg)

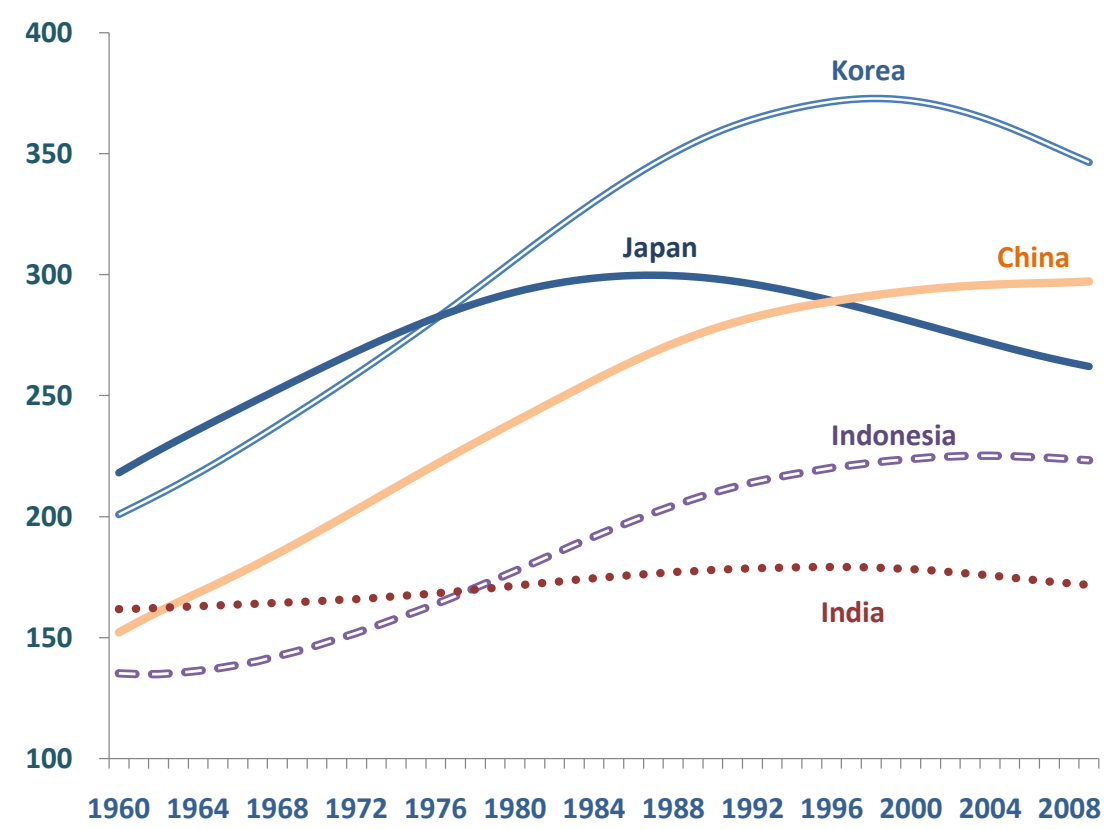

Source: Author's calculation from US Department of Agriculture data 